\title{
Cine de la crueldad y plataformas streaming: La erotización de la perversidad en las series mainstream Years and years y Chernobyl
}

\author{
Cinema of cruelty and streaming platforms: The eroticism of perversity in \\ mainstream series Years and years and Chernobyl
}

\author{
Carlos Fernández-Rodríguez \\ Universidad Rey Juan Carlos | 21001 Huelva| España | \\ http://orcid.org/0000-0001-5270-5772 | c.fernandezrod.2020@alumnos.urjc.es \\ Dr. Luis M. Romero-Rodríguez \\ Universidad Rey Juan Carlos | Camino del Molino, 5, Universidad Rey Juan Carlos, Edificio \\ Departamental 1, despacho 217. Fuenlabrada, 28942, Madrid| España| \\ http://orcid.org/0000-0003-3924-1517 |luis.romero@urjc.es \\ Dra. Belén Puebla Martínez \\ Universidad Rey Juan Carlos | Camino del Molino s/n Despacho 243 Edificio departamental I \\ 28943 Fuenlabrada, Madrid | España | \\ http://orcid.org/0000-0002-1481-4238|belen.puebla@urjc.es
}

Fechas | Recepción: 11/12/2020 | Aceptación: 16/02/2021

Resumen

Actualmente, alejados de aquellos tiempos de guerra entre el cine y la televisión de masas e inmersos en una cultura de las series cada vez más accesibles gracias a las plataformas streaming, las series empiezan a ser reconocidas como obras de arte que critican a las altas esferas de poder, signo propio de la tercera edad dorada de las series, y donde reside la verdadera originalidad audiovisual a ojos de las grandes audiencias en detrimento de un cine que parece cada vez más estancado o carente de interés. En plena revolución del panorama industrial del audiovisual, caracterizado por el éxito de las plataformas streaming, aparece un consumidor cada vez más democratizado, heterogéneo y cercano a la visión de "consumidor" más que de

\section{Abstract}

Today, far from those times of war between film and mass televisión and immersed in a culture of series that is increasingly accessible thanks to streaming platforms, series are beginning to be recognized as works of art that criticize the upper echelons of power, own sign of the third golden age of the series, and where true audiovisual originality resides in the eyes of large audiences to the detriment of a cinema that seems to be increasingly stagnant or uninteresting. In the middle of the revolution of the industrial panorama of the mainstream audiovisual, characterized by the presence of streaming platforms, increasingly democratized, varied, accessible, and close to the vision of "consumer" rather than "spectator", the mass audiovisual recover a cruel, hyper-realistic, 
"espectador". Adicionalmente, el audiovisual de masas recupera una visión perversa, hiperrealista, denunciativa y moralista que retrotrae al cine de la crueldad enunciado por André Bazin. Por todo ello, se diagnostica el fenómeno de la pornografía del horror, la estetización o la abyección cinematográfica, ya debatida por Jackes Rivette y Serge Daney en la segunda mitad del siglo XX, con el objeto de unir lo depresivo con el espectáculo en series actuales. Por todo ello, se ha procedido a la realización de un estudio de casos, mediante un análisis de carácter exploratorio y descriptivo, de las series Years and years y Chernobyl a fin de diagnosticar la presencia de una narrativa de prestigio en las plataformas streaming que cumplen como abyectas bajo el simulacro de lo denunciativo.

Palabras clave: cine de la crueldad, cultura mainstream, comunicación, abyección, streaming. denunciative and moralistic vision that goes back to the cinema of cruelty enunciated by André Bazin. However, the presence of horror pornography, a estheticization, abyection and the eroticism of cruelty, already debated by Jackes Rivette and Serge Daney in the second half of the 20th century, is perceived to combine the depressive with the playful in the eyes of spectators who are hungrier for perversity and cathartic plots. For all these reasons, a case study has been carried out, through an exploratory and descriptive descriptive analysis, of the series Years and years and Chernobyl in order to diagnose the presence of a prestigious narrative in the streaming platforms that comply as abject under the simulacrum of denunciation.

Keywords: cinema of cruelty; mainstream culture; communication; abjection; streaming.

\section{INTRODUCCIÓN}

Actualmente se respira la idea de que el entretenimiento domina gran parte de nuestra vida. Como si de alguna forma existiera la creencia colectiva de que el mundo, las personas, los animales o las cosas solo sirvieran para distraer o hacer feliz al individuo. Ya decía Zygmunt Bauman (2017, p. 30) que la búsqueda de la individualidad proviene de la desesperación por encontrarla y es, precisamente para este ser humano actual, a quien va dirigido el entretenimiento con el que tanto aspira a definirse y ser feliz. Es lo que se denomina la sociedad del entretenimiento: un mundo en el que se convence al sujeto de que el fin de la vida es ser gozada a través de una "fabricación industrial" de la diversión (Martínez López, 2011 , p. 7). Es decir, una sociedad en la que el hecho de vivir hambriento de ocio será referido como la única vía tomada en serio (al menos en los países occidentales) para el recorrido vital de un ser humano.

En consecuencia, cabría preguntarse qué es lo lúdico para el espectador de la sociedad del entretenimiento. Actualmente, podría definirse al público de espectáculos narrativos, especialmente audiovisuales (concretamente el cine o las series de televisión), como "turistas de las grandes emociones" (Ovejero, 2012, pp. 38-39) desde el sofá de casa, como si existiera un deseo interno de que los actores actuarán vilmente por ellos sin consecuencias físicas, legales o morales. Todo ello enmarcado en el epicentro de una cultura mainstream que parece estar encontrando en la ficción audiovisual contemporánea "la pornografía del horror" (Imbert, 2017, p. 17) como principal arma de seducción para la audiencia. Por consiguiente, se pretende realizar una revisión de literatura que explique el proceso mediante el cual, el cine y las series han llegado a ser consideradas «pornografía del horror» o «erótica de la crueldad». En primer lugar, se debe introducir el concepto de "cine de la crueldad», una tipología de cine que enmarcó a varios cineastas a mediados del siglo pasado y que en la actualidad está 
haciendo notar su presencia en la cultura mainstream a través de series de televisión, cada vez más cercanas gracias a las plataformas streaming como Netflix, HBO o Amazon Prime, que parecen estar encontrando en la visión desesperanzadora, morbosa y perversa del ser humano una hipervisibilización del horror en la cotidianeidad de sus tramas, lo cual termina por lograr que el espectador rechace otros argumentos o universos que puedan ser considerados como ingenuos o naif. Por tanto, se procederá mediante la revisión de literatura a una división entre el cine de la crueldad y la pornografía estética del cine.

En segundo lugar, se hace necesaria la reducción de diferencias entre la gran y pequeña pantalla en el momento presente y, con ella, más ventanas de producción y distribución llegando incluso al punto de saturación del contenido audiovisual. Dicho contenido parece enmarcarse en lo que podría denominarse "ocio deprimente», el cual, tras el escaparate snob de "series de prestigio", podría dar a entender que solo en la crueldad se hallan los asuntos trascendentales o culturales. Por tanto, parece de vital importancia reflexionar acerca del audiovisual contemporáneo de masas y su papel preponderante como exploración artística o pedagógica de la naturaleza humana o simplemente como una visión decadente e impactante de la misma.

\section{METODOLOGÍA Y PREGUNTAS DE INVESTIGACIÓN}

El presente estudio, de alcance exploratorio y descriptivo, ha consistido en una revisión histórica de literatura especializada en cine y series, así como en una exploración de artículos científicos en las bases de datos indexadas WoS y Scopus. El objetivo principal del estudio es evidenciar cómo las series de televisión se alimentan de una tendencia que proviene de un debate latente desde el cine de la crueldad de André Bazin y los críticos de la Cahiers du cinéma. Este debate al que se retrotrae este estudio es acerca de los límites de la crueldad y lo abyecto en la representación de tramas denunciativas y solemnes en el cine o series de prestigio. En consecuencia, se ha pretendido diagnosticar, mediante una revisión teórica inicial y un análisis de contenido de las series Years and years y Chernobyl, cómo las series de televisión contemporáneas se hallan envueltas en un alarde de espectáculo pornográfico y abyecto del horror como herederas de la crueldad cinematográfica. Las preguntas principales de esta investigación son:

- Q1: ¿Se ha instaurado el cine de la crueldad como una nueva norma en la cultura mainstream a través de la pornografía del horror y la erótica de la crueldad?

- Q2: ¿Se trata de un espectáculo pornográfico y morboso o una forma de denuncia?

- Q3: ¿Cómo es el lenguaje audiovisual que utilizan estas obras?

\section{REVISIÓN TEÓRICA Y PLANTEAMIENTO DEL PROBLEMA}

\subsection{El cine de la crueldad en la actualidad}

La crueldad o la abyección no es algo exclusivo de nuestra época actual, sino que resulta algo canónico en la historia del arte. Decía Sontag (2010, p. 68) "que un sangriento campo de batalla pudiera ser bello -en el registro sublime, pasmoso o trágico de la belleza- es un lugar común de las imágenes bélicas que realizan los artistas". Esta visión de la belleza del horror, podría dar como resultado un espectáculo del tormento reflejado en el arte que existe como una norma (Sontag, 2010, pp. 42-43). En el campo del cine, al igual que en la pintura, esta idea no se queda atrás. Pese a ello, existió una lucha entre los límites de la representación de la 
crueldad (que comenzó a tomar forma a raíz de la creación de la Cahiers du cinéma). El director francés Jacques Rivette manifestó en el artículo De l'abjection (1961) para la publicación francesa su indignación para con la abyección mostrada en la película Kapo (Gillo Pontecorvo, 1960). Dicho film contiene una escena en la que una prisionera judía se suicida lanzándose a la alambrada electrificada de un campo de concentración. La visión que utilizó Pontecorvo fue la de mostrar el cadáver en contrapicado a través de un travelling (F1) que describe el suicidio con todo detalle llegando a merecer, en palabras de Rivette, "el mayor de los desprecios" (Rivette, 1961, p. 54) como cineasta.

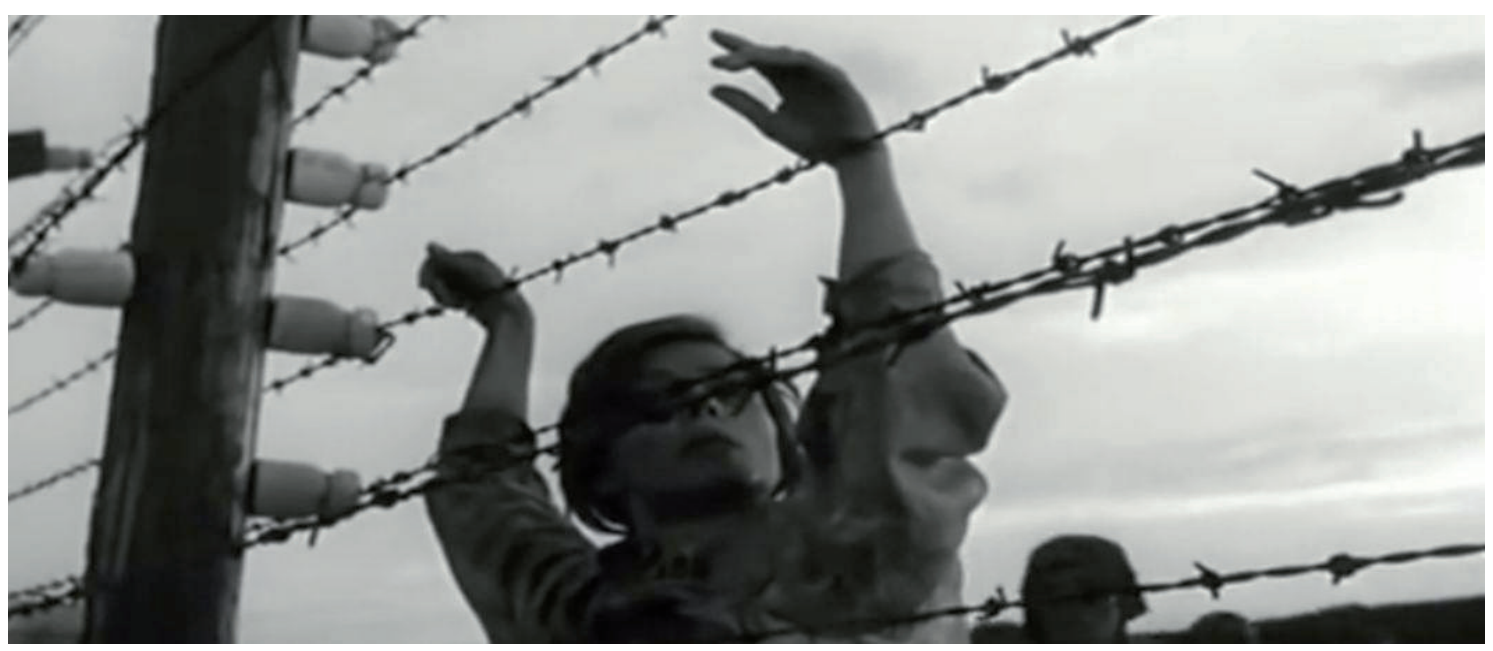

Figura 1. Kapo, Gillo Pontecorvo, 1960

Fuente: Slate.

Años más tarde, en 1975, algunos cineastas conformaron algunas cualidades que los convirtieron en "cineastas de la crueldad". Se trataba de seis cineastas concretos que aparecieron en la compilación de crónicas Le cinéma de la cruauté: de Bunuel à Hitchcock de André Bazin: Luis Buñuel, Akira Kurosawa, Alfred Hitchcock, Carl Theodor Dreyer, Preston Sturges y Eric Von Stroheim. Estos directores aparecían en la publicación debido a su visión moralista, subversiva y peculiar del mundo dando como resultado una gran influencia mundial en el campo artístico del cine (Truffaut, 1977, p. 10). De alguna forma, Bazin consideraba al cineasta de la crueldad un ser profundamente moral, no como el artista que busca (como decían algunos de Buñuel) "el escándalo por el escándalo, la violencia por la violencia" (Bazin, 1977, p. 93). Del mismo modo, las películas de Erich von Stroheim eran consideradas por Bazin como una "tesis social o moral" (Bazin, 1977, p. 23) en las que el cineasta llegaba a mostrar una psique profundamente "dominada por la obsesión sexual y el sadismo y que se desarrolla bajo el signo de la violencia y de la crueldad" (p. 23). Por tanto, como puede apreciarse en algunas de las citas ya mencionadas de Bazin en El cine de la crueldad, se vislumbra una fascinación moral en el que el sadismo, la crueldad o la violencia eran reflejo de una genialidad puramente humanista. Es decir, cuando se habla del cine de la crueldad se habla del triunfo de la dignidad humana mediante el reflejo de lo subversivo o perverso.

Treinta años más tarde, el crítico Serge Daney decidió resucitar en 1992 el debate de la abyección, el cine de la crueldad y los límites de la representación en el cine llegando a afirmar, al respecto del cine de la crueldad, que "la carnicería industrial y la condición humana no son incompatibles" (Daney, 1992). Daney, en su artículo El travelling de Kapo, comparó Kapo con el documental Noche y niebla (Alan Resnais, 1955) afirmando que "la pornografía 
artística" de Kapo era indignante a diferencia del "retorno honesto" de las imágenes de Noche y niebla, las cuales permitían al espectador reconocer la imposibilidad de narrar y la posibilidad de hacer un alto en la continuidad de la historia.

Es por ello que Daney diferencia entre lo cruel y lo abyecto. Según Rivera-García (2016): "Daney, como discípulo aventajado de Bazin, considera que el arte de la crueldad está de buen lado". Es decir, lo que Daney pretendía afirmar era que la abyección en la representación podría entenderse como la parte pornográfica y estetizada de estas películas de la crueldad. Por consiguiente, podría decirse que, desde la visión de Daney, existen dos formas distintas de acceder a la crueldad: la moralista (propia de los cineastas de la crueldad de Bazin) y la abyecta (propia de los pornógrafos estéticos). Un ejemplo de abyección estética podría darse en la película Titus (Julie Taymor, 1999), en la que la representación exploraba distintos niveles de abyección a través de una revisión del género de terror que oscilaba a medio camino entre representaciones realistas y estilizadas (F2) buscando, por encima de todo, el placer "de visualización masoquista en las audiencias" (Starks, 2002, p. 122). En definitiva, Titus podría servir para ilustrar un camino cinematográfico más posmoderno que moderno, con una crueldad más gráfica que sutil y humanista, más hiperrealista que realista.

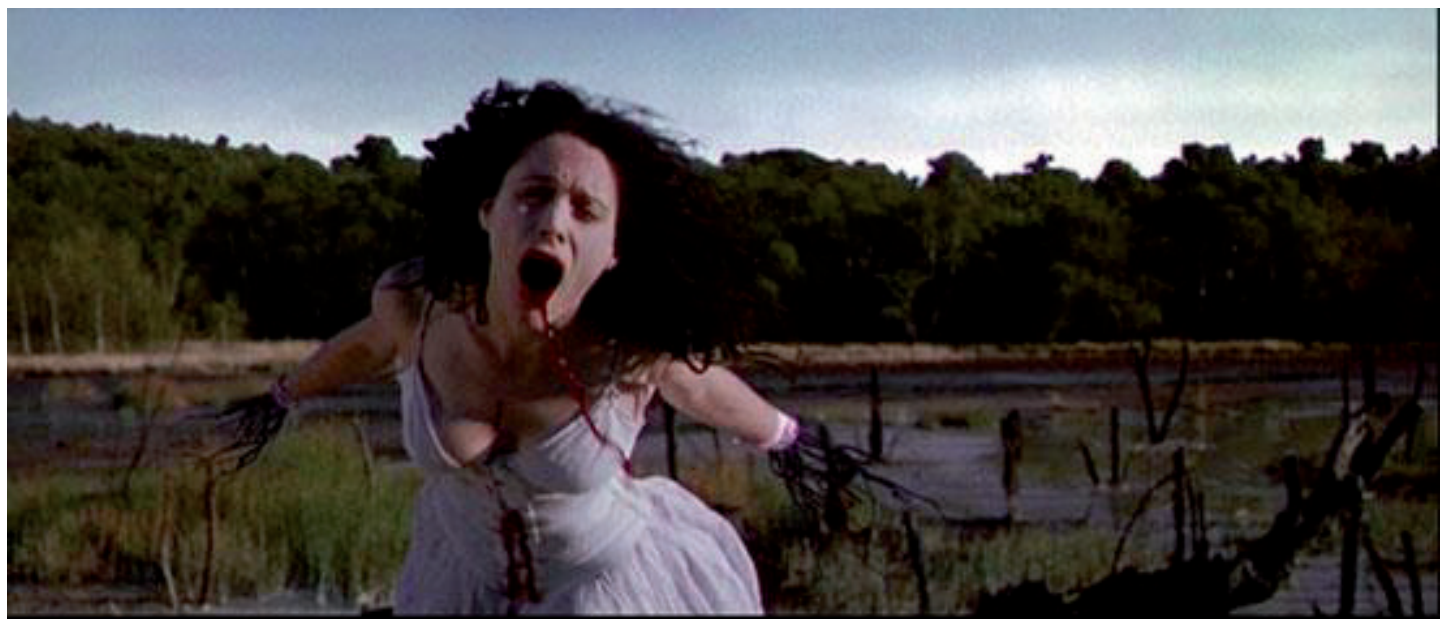

Figura 2. Titus, Julie Taymor, 1999

Fuente: https://www.pinterest.co.uk/pin/415316396873102597/

Por todo ello, el cine de la crueldad parece haber sido amparado en la actualidad en los brazos del espectáculo y de la pornografía del horror llegando a obtener premios de prestigio en festivales cinematográficos más prestigiosos, aquellos de clase $A$, desde principios de nuestro siglo. Prueba de ello son películas actuales de la crueldad como Funny games (Michael Haneke, 1997), La cinta blanca (Michael Haneke, 2009), Irreversible (Gaspar Noé, 2002), Anticristo (Lars von Trier, 2009), Leviatán (Andrey Zvyagintsev, 2012), Fuerza mayor (Ruben Östlund, 2014), Playground (Bartosz M. Kowalski, 2016), Algunas bestias (Jorge Riquelme Serrano, 2019), Langosta (Yorgos Lanthimos, 2015) o Beginning (Dea Kulumbegashvili, 2020). Dichos títulos contienen tramas denunciativas, apocalípticas, estilizadas, sermoneadoras y refinadas audiovisualmente. Del mismo modo, contienen un componente, en ocasiones y no siempre, abyecto y pornográfico que pretende la inmersión del espectador en la experiencia hiperrealista de la crueldad, oscilando entre la incomodad y lo insoportable, pero siempre acogidas bajo el impacto o el shock al espectador. 


\subsection{Nuevos escenarios: Cultura mainstream, streaming y la erótica de la crueldad}

Resulta necesario recordar que vivimos inmersos en la cultura mainstream, es decir un modelo propio de las industrias culturales destinado a fabricar cultura para la mayor cantidad de audiencia posible. Todo ello dando pie a fomentar una "guerra mundial por los contenidos" (Martel, 2011, p. 18) que no es otra que el conflicto industrial por el entretenimiento y los ojos del mundo. Algunos críticos han llegado a definir a la cultura actual como un "divertimento", un pasatiempo elevado del que solo puede esperarse una victoria de la civilización del espectáculo (Lipovetsky, 2012) y cuyo rechazo podría suponer una resistencia a la expansión de los ideales políticos, los gustos estéticos y la deformación de la cultura popular (MartínBarbero, 2012, p. 83).

Además, resulta patente que los espectadores actuales se hallan en un momento convulso en la historia del consumo de entretenimiento audiovisual tanto en series como películas, al ver cómo la tecnología se multiplica año a año y se facilita el acceso al audiovisual a través de plataformas streaming (Ilegando estas plataformas a producir y distribuir películas y series de gran éxito en la última década). Por consiguiente, se evidencia que las plataformas streaming han entrado en la industria cultural del audiovisual mainstream llegando a desbancar a las salas de cine como las principales exhibidoras en beneficio de las pequeñas pantallas (televisión, smarthphones, tablets...) modificando el modelo de negocio con el fin de fomentar "una cultura industrial, flexible y basada en el let the consumer decide" (Neira, 2017, p. 48). Según Heredia Ruiz (2016, p. 277): "Netflix y el surgimiento de Internet han transformado profundamente las ventanas clásicas de distribución del cine, así como la industria televisiva”. Este modelo de negocio ha fomentado una cultura irracional, muy variada, democratizada, confusa y a la carta en la que "la realidad parece ser un efecto del entretenimiento" (Chul-Han, 2018, p. 63) dando lugar a una "cultura de mercado", que no "arte" (Martel, 2011, p. 18). En esta misma línea, el filósofo Guy Debord (2015, p. 44) llegó a afirmar en 1967 que "el espectáculo es el mal sueño de la sociedad moderna desencadenada, que no expresa en última instancia más que su deseo de dormir" terminando por concluir que "el espectáculo es el que vela por ese sueño".

A este respecto, la cultura dominante de masas ha terminado por fomentar una erótica de la crueldad, enunciada como un símbolo moderno frente a valores más compasivos o humanistas que se ha visto más reforzado gracias a las influencias de diversos productos culturales. En definitiva, una forma de "gozar del dolor del semejante" (Goldstein, 2006); un placer que, en nuestra época actual, se caracteriza "por gozar de una crueldad que ya no requiere de prejuicios incriminantes" (op. cit.).

Por otro lado, Goldstein (2006) afirmaba que el principal factor que nos permite gozar de la crueldad en nuestra cultura actual es la homogenización y "globalización de significantes" que solo pueden entenderse a través de la subjetividad y del individualismo. Adicionalmente, este individualismo podría conllevar a la cultura a una deriva abyecta tal como afirma Suzunaga Quintana (2013, p. 251) al respecto de la erótica de la crueldad: "Se presenta una suerte de empobrecimiento erótico como efecto de los excesos, tanto de esperanza como de desesperanza. En consecuencia, una suerte de empobrecimiento de la subjetividad y de la economía psíquica, lo que resulta típico del capitalismo". Por tanto, la erótica de la crueldad denota un placer en el sufrimiento de ciertos colectivos sociales, pudiendo llegar a ser magnética dada la globalización de significantes y la presencia del "todo vale" en la subjetividad individual tan característica de nuestra época posmoderna. De esta manera, el 
espectador puede vivir en convivencia con temáticas naif y temáticas abyectas a diarias con un único denominador común: la pornografía de la experiencia inmersiva.

Muy bien representada en el cine, pero en absoluto ausente de la literatura, esta crueldad se convierte en espectáculo, en esparcimiento que se agota en la provocación de emociones tan intensas como vicarias. Asesinos en serie, policías sádicos, violadores, todo tipo de psicópatas pueblan miles de páginas y de fotogramas que no tienen otro sentido que el entretenimiento, el cual parece ser la meta de la mayor parte de la producción cultural contemporánea (Ovejero, 2012, p. 35).

\subsection{Series de televisión y pornografía del horror}

Por lo que se refiere a las series de televisión mainstream, es adecuado considerar el punto de partida tan ignorado que han vivido dentro del medio audiovisual. Es decir, como un producto que, comparado constantemente de forma histórica con el cine, ha ido alterando su percepción desde hace unos pocos años. Sin embargo, aunque durante años las series de televisión fueron relegadas a una vulgar cultura de masas, en el momento actual son comparadas con el arte o la literatura (Muñoz-Fernández, 2016, p. 70).

Por otro lado, Joyard (2011, p. 14) determinó que "liberadas del más mínimo complejo de inferioridad, ahora las series pueden contarlo todo, sin plantearse la paralizando pregunta acerca de su legitimidad". Esta ausencia de complejo viene de la llamada edad dorada de las series. Según Cascajosa Virino (2005) ha habido tres edades doradas de las series: La primera se dio entre los años cuarenta y mediados de los cincuenta y estaba enfocada en el drama antológico. La segunda edad dorada tuvo lugar en los años ochenta y principios de los 90 (por ejemplo, Twin peaks) y una tercera edad dorada (la actual) que, según Benchichá López (2015, p. 135), aborda temas como "el aborto, derechos de los prisioneros, derechos de los trabajadores y derechos sindicales, división racial, atentados terroristas, prostitución, drogas, fraude electoral, economía sumergida o el genocidio".

En relación a esta nueva forma de consumo, Reviriego $(2011$, p. 8) añadió que "la cinefilia es ahora telefilia y su culto se ha vuelto mainstream". En consecuencia, y con dicho salto de calidad, han ido apareciendo un gran número de series en los últimos años que han tratado "compartir" el público de las salas con público televisivo. Según el crítico cinematográfico A. O. Scott (2010): "La relación entre el cine y su público, que ha perdurado durante más de un siglo, ha llegado a un punto difícil".

Asimismo, en la actualidad se vive un momento en el que la rutina de los espectadores con plataformas streaming se está amoldando a lo que podría denominarse un «canon de la crueldad»: asesinatos, maltratos, vejaciones y, en general, el reflejo de una pornografía de la misantropía y la ansiedad de una forma hiperreal e inmersiva como símbolo del entretenimiento. Según Tait (2008, p. 107) el termino de 'pornografía' acaba por acoplarse a los contextos contemporáneos de la audiencia con el fin de focalizar sus ansiedades públicas a la vez que se excluye la comprensión del delito concreto que pueda estar representado, del mismo modo que las miradas que puedan llegarse a dibujar en los rostros del público. Además, esta pornografía actual, al tratarse de una obra de la crueldad, podría decirse que viviría enfocada, casi por completo, en la psicología interna de los personajes (Laing, 2020).

Así pues, esta visión cruel de la psicología interna de los personajes ficticios parece abordar una triada de la representación actual latente en cualquier tipo de obra audiovisual (sea más o 
menos comercial): Violencia, muerte y horror (Imbert, 2017, p. 18). En consecuencia, el cine el cine terminaría por proveernos solo de los «referentes fuertes»: Cuerpo, sexo, identidad, horror y muerte (p. 725). Todo ello terminaría por resucitar lo que George Gerbner definiría como Mean World Syndrome (Morgan y Shanahan, 2010, p. 339), una teoría que llevaría al espectador a percibir que la crueldad mostrada en las ficciones televisivas tenía un fiel eco en la realidad. Por tanto, se comprende que la vida actual en las sociedades industrializadas funcionaría esencialmente a través de estímulos simples tales como el deseo sexual, la voracidad, el sadismo, la destructividad o el narcisismo, siendo todos ellos comunicados al espectador a través de los medios de comunicación de masas tales como el cine, la radio, la televisión o los periódicos (Fromm, 2004, p. 245). A todo esto, según Villanueva et al. (2013, p. 591) "la violencia en televisión, sea ficticia o real, interesa y atrae a los espectadores". Todo ello da como resultado un morbo que funcionaría como el principal interés, casi como una cata de lo destructivo y negativo (p. 591). Por otro lado, esta crueldad y violencia audiovisual, inmersa en la rutina de los espectadores, suelen referirse a productos audiovisuales que comparten una línea temática común en los que se abordan temas como "la cultura del poder y la imagen o el fracaso institucional y político de la era posindustrial" (Reviriego, 2011, p. 7).

En lugar de definir la televisión con la pretensión de grandeza objetiva, la palabra prestigio, con sus implicaciones snob, era indicativa de una verdad quizás involuntaria sobre estos programas. Es una valoración clasista, que implica inaccesibilidad, escasez, pero también influencia e importancia generalizadas. No es fácil, esponjoso o divertido porque, en algún lugar profundo de la psique estadounidense, todavía existe una creencia puritana de que las cosas divertidas no pueden ser también serias. La televisión de prestigio es exigente, algo que crea una implicación clasista adicional sobre su audiencia. (VanArendonk, 2020)

En cuanto a la anterior cita, puede contemplarse como la autora disecciona el fenómeno de las series de televisión de prestigio como un símbolo snob y clasista que termina por invisibilizar la idea de que lo "sencillo" o "divertido" pudiera ser serio o trascendental. Adicionalmente, VanArendonk (2020) llegó a afirmar que el fenómeno de las series de prestigio, aquellas que son más desesperanzadoras y deprimentes, se está empezando a transformar dada la influencia del coronavirus y de la ansiedad política del último año: “¿Quién quiere sentirse frustrado o entristecido por su entretenimiento cuando el mundo exterior se siente como un lugar suficientemente brutal?". Sin embargo, a día de hoy aún se dan grandes series y películas de autor que insisten en estetizar el fin del mundo. Según Argullol (2007, p. 12) "La nada es, para una cultura espectral, el horizonte más excitante". Para Imbert (2019, p. 23), en el cine actual "los imaginarios proyectados en el futuro reflejan las inquietudes de hoy, la inestabilidad del presente, la incertidumbre vinculada a la ausencia de futuro, las turbulencias políticas y las amenazas económicas".

\section{RESULTADOS: ANÁLISIS DE CONTENIDO DE LAS SERIES}

\subsection{El caso de Years and years}

Para profundizar en la erótica de la crueldad en el audiovisual mainstream contemporáneo se procederá a realizar un breve análisis de la pornografía del horror habida en el caso de la miniserie británica Years and years, creada por el inglés Russell T. Davies, compuesta por una única temporada de 6 episodios y estrenada el 14 de mayo de 2019 en la cadena BBC One. Se 
trata de una serie que narra la historia de la familia Lyon, residente en Manchester, del 2019 al 2034. A lo largo de 15 años, la unidad familiar se enfrentará a terroríficos y convulsos cambios políticos, tecnológicos y económicos que les afectará personal, cultural y socialmente. Algunos de los motivos que ha llevado a la selección de esta miniserie es su carácter mainstream, lo reciente que es, la conciliación temática entre el mundo de la distopía, la institución política y el abyecto mundo de los votantes y su misántropa forma de entender el mundo sin negar ciertos rasgos propios de un folletín con las que aspirar a disfrazar lo político y abyecto de denuncia moral, de sermón al espectador. Para Santos (2019, p. 51) "la distopía ilustra el fracaso colectivo de la humanidad a la hora de enfrentarse con los principales problemas y amenazas que se ciernen sobre nuestro futuro" llegando a ser "magnificados hasta cobrar dimensiones monstruosas". En el momento actual, las series de televisión están optando por estas narrativas distópicas como puede verse en otros casos como en las series El colapso (2019) de Jérémy Bernard, Guillaume Desjardins y Bastien Ughetto, El cuento de la criada (2017) de Bruce Miller o The leftovers (2014) de Damon Lindelof y Tom Perrotta o películas contemporáneas como El nuevo orden (2020) de Michel Franco.

La secuencia inicial nos introduce en el año 2019, en el salón familiar de cada uno de los Lyon a través de una secuencia de montaje paralelo en la que se nos presenta a los miembros de la familia como si fueran un solo personaje: No se separan del teléfono móvil sin dejar de mirar la televisión, un dispositivo Ilamado Signor (un asistente virtual que funciona por voz) está presente en cada una de las casas familiares, filtros en las caras de los individuos de forma literal o videollamadas constantes. Pese a estar rodeados de tecnología, parecen vivir adaptados y en harmonía (puede que se traten de los únicos minutos de paz que la familia vivirá a lo largo de la serie). Todos visionan una tertulia política televisada en la que una política sensacionalista y demagoga llamada Vivienne Rook realiza polémicas declaraciones en televisión:

Os juro que ya no comprendo el mundo actualmente. Hace unos años todo tenía sentido: La izquierda era la izquierda, la derecha era la derecha, América era América... y ni siquiera podía señalar Siria en un mapa. Antes acostaba a los niños, apagaba la luz y esperaba con ilusión otro día. Ahora tengo miedo. Cada día. (Vivienne Rook, guionizado por Russell T. Davies)

Rook termina por utilizar un lenguaje soez y populista que invita a tratar temas complejos de forma sencilla y rompe la cuarta pared con los televidentes de la tertulia, pero también con los espectadores de Years and years ya que su rostro ocupa todo el cuadro mientras mira a cámara. Sin detenernos en exceso en el lenguaje político de la serie, la ruptura de la cuarta pared de Vivienne Rook supone el detonante narrativo que iniciará un viaje de la «inocente televisión» a la realidad, de la calma del sofá a la polarización política y de la paz al caos.

Se dan varias secuencias de montaje a lo largo de los episodios que narran tantos sucesos apocalípticos que resulta difícil mencionarlos todos: Se ha derretido el polo norte, los bancos quiebran, las farmacias no tienen medicamentos, los analistas de datos controlan las interferencias de otros países, en Grecia se inicia un "Grexit», Hungría se declara en la bancarrota, Italia sufre el yugo de la ley marcial tras la dimisión de su gobierno, las inundaciones gobiernan el mundo, bombas sucias explotan en las ciudades creando radiación, se dan constantes apagones que podrían venir de diversas fuentes, se extinguen las abejas, los periodistas que se enfrentan al gobierno empiezan a ser vetados o hay una pandemia mundial surgida de un mono. De alguna forma, la serie parece animar a abandonar el barco de la 
especie humana y sumergirnos en la maquina como consuelo de algo mejor, como puede apreciarse en la escena en la que Bethany se instala el teléfono móvil en su propia mano (F3).

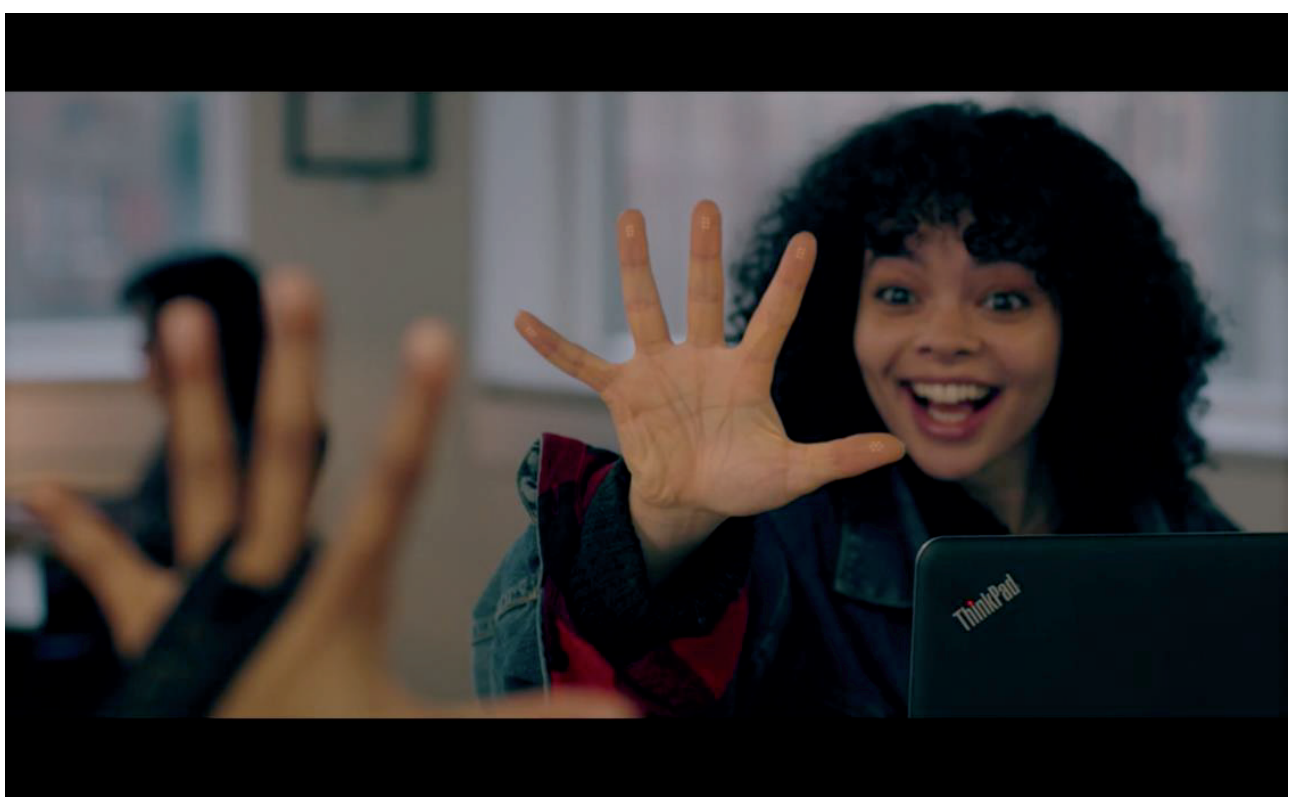

Figura 3: Years and years, Russell T. Davies, 2019

Fuente: HBO.

Years and years enfoca la obsesión en la especie humana por metamorfosearse en una máquina a la par que la deshumanización ligada a este hecho trae como consecuencia varias catástrofes repletas de muerte y miseria en las que el mundo se derrumba debido al "inmovilismo" del pueblo (a lo que la abuela Muriel echa directamente la culpa de todos los acontecimientos de la serie):

(...) No cambia que todo sea culpa vuestra. De todos. Los bancos, el Gobierno, la recesión, Estados Unidos, la Sra. Rook. Todo lo que ha ido mal es culpa vuestra. Todos somos responsables, cada uno de nosotros. Podemos pasarnos el día culpando a otros. Culpamos a la economía, a Europa, a la oposición, al clima y al vasto e incontrolable curso de la historia, como si no dependiera de nosotros, seres indefensos e insignificantes. Pero sigue siendo culpa vuestra (...).

A pesar de este discurso sermoneador y denunciativo que pretende envolver la serie de un tono fabulesco y moral al final de la misma, la serie muestra consecuencias terribles para aquellos que se enfrenten a las injusticias (radiación, muerte en el mar, robo de identidad, venganzas varias...). Russell T. Davies lleva a los personajes al borde de un precipicio catártico que se resuelve con alejarse del ser humano y fundirse con la máquina. De esta manera, lo que comienza por ser una crítica de un orden moral catastrófico en las narrativas termina por ser una banalización de la propia crítica en nombre del entretenimiento, los excesos estéticos y la pornografía del horror ("mostrar más que contar").

\subsection{El caso de Chernobyl}

En segundo lugar, se procede a realizar un breve análisis de la pornografía del horror en la miniserie estadounidense Chernobyl creada por Craig Mazin (único guionista de toda la serie), compuesta por una única temporada de 5 episodios y estrenada el 6 de mayo de 2019 en HBO. 
En este caso, se narra la historia de la explosión sucedida en la Central Nuclear de Chernóbil el 26 de abril de 1986 en Ucrania desde distintos puntos de vista a fin de utilizar dicha catástrofe como una lectura de la caída de la URSS (sin olvidar que se trata de una ficción que retrata un pasado soviético desde una visión estadounidense). Algunos de los motivos que llevó a seleccionar esta miniserie fueron el carácter mainstream de la misma, lo reciente que es, su prestigio (Golden Globe 2019 a la mejor miniserie dramática) y el uso de una catástrofe real, con todo su arsenal de denuncia, de una forma abyecta gracias al uso de la, cada vez más habitual, pornografía estética que critica a instituciones políticas a la vez que seduce a los ojos del espectador mediante planos secuencia, slow motions, pictorialismos varios y una fotografía preciosista y tenebrista.

Relato planificado con excelsa minuciosidad, exhibición de estrategia política llevada a cabo hasta las últimas consecuencias (con el desbordante avanzar de la técnica moderna), ejemplo de los riesgos de la mentira en la vida pública, cúmulo de hilos argumentales articulados cual cubo de Rubik existencial y proyección de percepciones presentadas como guante de lino forjado en hierro, la serie Chernobyl, que se balancea en la frontera entre lo real y lo trascendente, se caracteriza por la ecuanimidad entre el poder evocador de la imagen y la palabra. (Pallarès-Piquer et al., 2019, p. 789)

El prólogo del primer episodio de Chernobyl es una anticipación catastrófica en el que se revela al espectador el suicidio de su protagonista, el físico nuclear Valery Legásov (Jared Harris), quien está grabando unas cintas en las que narra la historia real que la URSS le impidió difundir a cuenta de no acabar con la imagen del Estado a ojos de los países enemigos, antes de dar comienzo la historia. Se trata de un monólogo el que narra la verdad sucedida sobre el accidente habido en la central nuclear de Chernóbil. En dicho discurso, Legásov se cuelga del techo en presencia de su mascota.

El guionista Craig Mazin establece en este monólogo, antes de presenciar nada de lo acontecido en la historia, varias cosas: En primer lugar, que lo que la audiencia va a ver a lo largo de la miniserie está basado en documentos reales de Valery Legásov; en segundo lugar, que el personaje principal de la historia se suicida al final de la misma y, en tercer lugar, que no hubo ni habrá justicia para la historia que se abre ante el espectador. La desesperanza está certificada casi desde el primer minuto ya que el espectador conoce de antemano que todo saldrá mal, para que así no quepa en la seriedad y solemnidad dramática de la propuesta el más mínimo espejismo de una recompensa moral o satisfactoria al final del duro viaje que se propone al que visiona. Podría decirse que esta escena no funciona tanto como un prólogo como una advertencia al espectador, al cual se le previene de la crudeza de la historia, que además es real (a diferencia de la ficción de Years and years), lo que supone una mayor cercanía con la realidad y, por tanto, más terror.

Entre algunos de los momentos más destacados en la crueldad de la serie destaca el colocar la cámara dentro del piso del bombero y de su mujer (los Ignatenko) para mostrar la explosión (F4), dejando entrever que la crueldad que se va a presenciar tendrá consecuencias en la rutina, en el interior de las vidas y de las casas de las personas cercanas a la central. Tras la explosión, se da un momento estetizado con la belleza de las imágenes y un montaje a cámara lenta en el que decenas de espectadores curiosos de Prypiat se asoman a un puente (posteriormente conocido como "el puente de la muerte"), en el que contemplan las luces que desprende la radiación. En ese instante comienza a llover ceniza radioactiva, que el director 
Johan Renck asemeja a la nieve, con la que todos los allí presentes juegan o se hipnotizan mirando (casi del mismo modo que los espectadores de la serie). Esa ceniza radioactiva en la que bailan, juegan y admiran es lo que matará a dichos inocentes de cáncer en pocos años. Se trata de una escena dotada de una siniestra belleza, solemnidad y crueldad en la que la presencia de la muerte es algo lúdico y hermoso (F5).

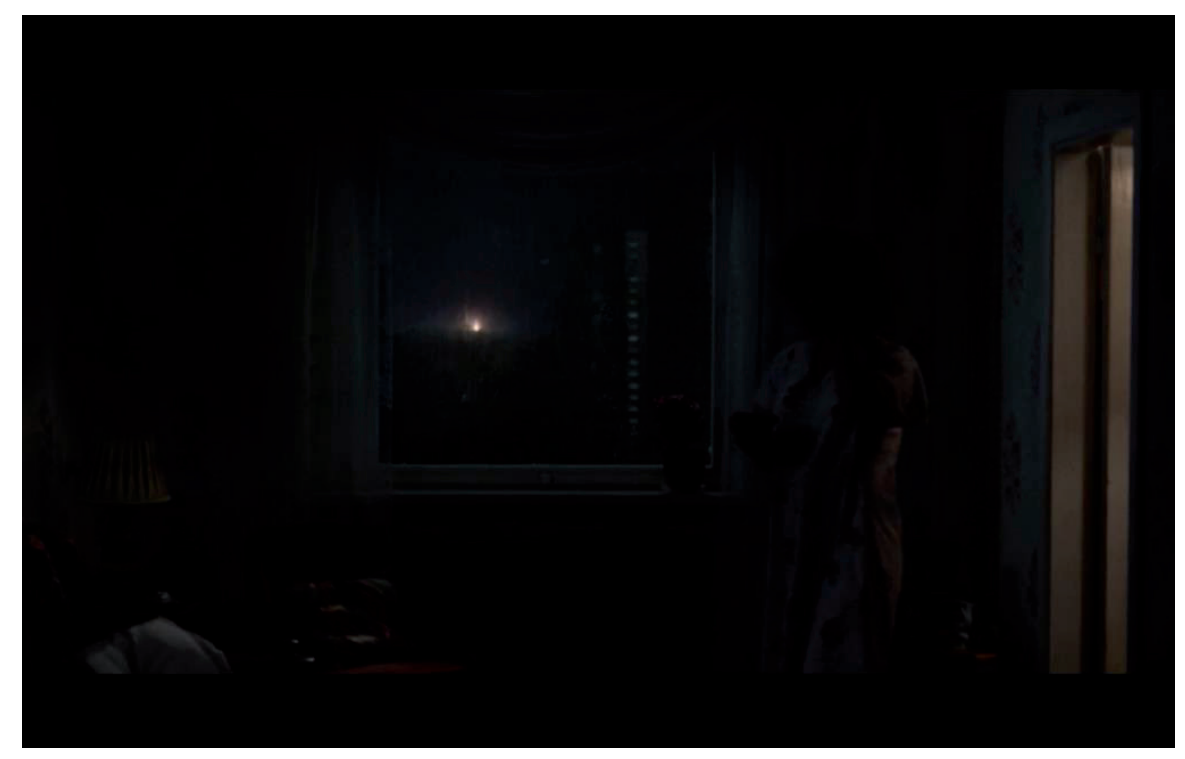

Figura 4. Chernobyl, Craig Mazin, 2019

Fuente: $\mathrm{HBO}$

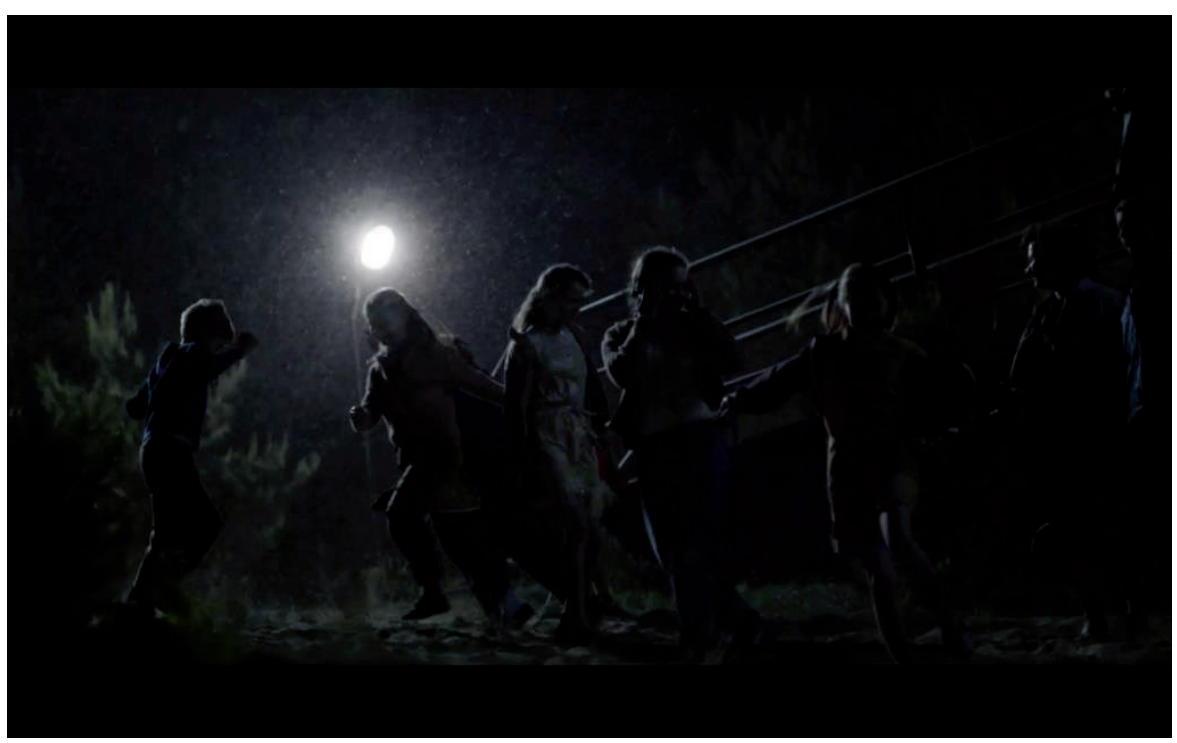

Figura 5. Chernobyl, Craig Mazin, 2019

Fuente: $\mathrm{HBO}$.

Esta inmersión en la muerte y la crueldad acontecida en nombre de la ineptitud y la maldad política tiene uno de sus epicentros impactantes en el capítulo 4, en el que el espectador conoce a un joven soviético que es enviado a Chernóbil (junto a 150.000 hombres más llamados a acortar su vida o a una promesa de cáncer en pocos años debido a la necesidad de limpiar de radiación las zonas afectadas), llamado Pavel (Barry Keoghan), personaje que tiene la misión, junto a Garo (Alexej Manvelov) y Bacho (Fares Fares) de asesinar a todos los animales vivos que encuentren debido a su contaminación al estar expuestos en las zonas. Las 
escenas de la "cacería" son de una crudeza visceral e impactante en la que el espectador puede apreciar los perros y gatos escondidos para no ser sentenciados. No solo se muestra a un perro con las tripas desparramadas, sino que se muestra a una perra con una camada de cachorros a punto de ser matados y se percibe, debido al sonido de los disparos -ya que la escena sucede fuera de campo- los asesinatos a dichos animales en tiempo real. Las imágenes de padecimiento son mostradas con un alto nivel gráfico en animales y seres humanos, mientras que algunas escenas (como la del "puente de la muerte") estetizan con cámara lenta la presencia del fin de la existencia.

Como puede apreciarse tras el análisis de contenido, el producto de entretenimiento mainstream Chernobyl tiene muchas cualidades abyectas y perversas en cuanto al cine de la crueldad dentro de su trama: Un dolor inaguantable causado por las quemaduras radiactivas, fetos muertos por radiación, cachorros asesinados con un arma de fuego, políticos fanáticos e irresponsables, suicidios y miles de vidas perdidas en nombre de un estado obsesionado con no reconocer sus fallos. En definitiva, Chernobyl no es simplemente una lúdica y entretenida exploración, a modo de macabro turismo audiovisual, de la crueldad humana sino un recordatorio de lo malvada e irresponsable que es la política y de las consecuencias de todo aquel que se enfrente a ella: La muerte o el suicidio debido a la frustración de no poder cambiar las cosas. Por consiguiente, aunque exista una lectura moral, esta se encuentra por debajo de la visión pornográfica, estetizada e industrializada de la desgracia disfrazada de sermón.

\section{DISCUSIÓN Y CONCLUSIONES}

Si bien el cine de la crueldad de André Bazin tenía un fin moralista, actualmente existe un deleite en la miseria humana. El uso de la pornografía del horror, la visión hiperrealista de la denuncia moral y la caligrafía abyecta habida en series como Chernobyl y Years and years advierten de una preocupante industrialización de la pornografía estética del horror en nombre de la denuncia institucional y moral. En definitiva, la apocalíptica visión de la industria cultural "de prestigio» que llega a banalizar, por su "canon de la crueldad», las tragedias o dramas que denuncian. El cineasta de la crueldad, como pensaba Bazin, muestra más que narra y puede llegar a asesinar la narración o la retórica en beneficio de la evidencia y es precisamente esta visión subversiva la que se multiplica en un audiovisual, como el actual, que parece correr el peligro de ser un sinfín de imágenes abyectas directas al estómago del espectador más que a la razón.

Es evidente que existe un fin denunciatorio y un pretexto moral en la realización de ambas series, que ya tenían cineastas como Buñuel, Hitchcock o Dreyer (estos tres con una trascendencia real pese a la incomodidad y sordidez de sus historias), moralismo y crueldad. Sin embargo, al cine de la crueldad actual, cada vez más masivo, se le añaden ligeras pinceladas de folletín, suspense, abyección y espectáculo. Es decir, la idea de que lo "deprimente" debe ser divertido para ser consumido mediante el simulacro de lo trascendental. Es decir, una lógica de series televisivas de la tercera edad dorada que ha encontrado en el alarmismo apocalíptico y en el apego a la muerte y la catástrofe un territorio en el que cultivar entretenimiento. No se trata de que ambas series no exploren problemas importantes, sino de una ignorancia absoluta a la esperanza en nombre del chapoteo estético de la perversidad de nuestra especie. Esta es una evolución que, de alguna forma, ya predijo 
Serge Daney en su artículo El travelling de Kapo, llegando a predecir que el cine evolucionaría a un sentido más gráfico y menos ético en nombre de un cine moderno saturado de crueldad.

En conclusión, ambas series aventuran el regodeo trágico de los problemas mundiales como mecanismos para explorar la abyección residente en sus narrativas bajo el simulacro de la denuncia y el sermón al espectador. El entretenimiento de estas series parece aspirar a un nihilismo posmoderno e individualista en el que se respira el deseo de reinvención propia, de definición individualista y de desconfianza por el ser humano. En definitiva, un audiovisual que parece aspirar a que el espectador sea sermoneado por la maldad de la pantalla, que reconoce como propia, pudiendo llegar a disfrutar de las miserias, a las que ya se ha acostumbrado, y que siente que no puede cambiar. En conclusión, la banalización dramática de los problemas reales del mundo en nombre de la todopoderosa sociedad del entretenimiento. Mientras Years and years enfoca su pesimismo en el mañana, Chernobyl lo hace en el ayer, y el espectador, en el momento presente, cansado y hastiado, prepara palomitas para ver arder el mundo vía streaming. De esta manera, ambas series, pese a su alta calidad técnica, son parte de una industrialización de una crueldad pornográfica que poco tiene que ver con la visión que soñó André Bazin.

Por consiguiente, respondiendo a las preguntas de investigación iniciales, se afirma que el cine de la crueldad más pornográfico, tanto en cine como en series de televisión, se está instaurando con el deseo contemporáneo de evasión, impacto, shock y apocalipsis en las tramas narrativas. Por otro lado, muchas denuncias de estas tramas funcionan como una simple coartada para explorar distintos niveles de abyección audiovisual mediante un lenguaje hiperrealista e hiperestilizado con el que se pretende involucrar más al espectador en el papel de los personajes habidos en las tenebristas narrativas.

\section{Referencias}

Argullol, R. (2007). El fin del mundo como obra de arte. Acantilado.

Bauman, Z. (2017). Vida líquida. Austral.

Bazin, A. (1977). El cine de la crueldad. El mensajero.

Benchichá-López, N. Y. (2015). La tercera edad dorada de la televisión: Battlestar Galáctica y las nuevas formas de pensar, hacer y consumir el drama televisivo norteamericano [Doctoral dissertation, Universitat Ramon Llull]. https://bit.ly/3eaGnAl

Cascajosa-Virino, C. (2005). Por un drama de calidad en televisión: la segunda edad dorada de la televisión norteamericana. Comunicar: Revista científica iberoamericana de comunicación y educación, 25(2). https://doi.org/10.3916/C25-2005-157

Chul-Han, B. (2018). Buen entretenimiento. Herder.

Daney, S. (1992). El travelling de Kapo. Traffic ,4, 5-19.

Debord, G. (2015). La sociedad del espectáculo. Pre-textos.

Fernández-Villanueva, C., Revilla-Castro, J. C., González-Fernández, R., y Lozano-Maneiro, B. (2013). Violencia en la televisión. ¿Desagradable, interesante, o morbosa? Revista Latina de Comunicación Social, 68, 588-594. https://doi.org/10.4185/RLCS-2013-991

Fromm, E. (2004). Anatomía de la destructividad humana. Siglo veintiuno.

Goldstein, M. (2006). Crueldad y terror en la estructura social y subjetividad contemporáneas. Letra Urbana, 5. https://bit.ly/2ZiGALK

Heredia, V. (2016). Revolución Netflix: Desafíos para la era industrial. Chasqui: Revista latinoamericana de Comunicación, 135, 275-295. https://bit.ly/2Y91ihl 
Imbert, G. (2017). Cine e imaginarios sociales: el cine posmoderno como experiencia de los límites. Cátedra.

Imbert. G. (2019). Crisis de valores en el cine posmoderno. Cátedra.

Joyard. O. (2011). La edad de oro, ¿̇y después...? Caimán cuadernos de cine, 47, 14-16.

Laing, N. (2020). On the Possibility of a Cinema of Cruelty. https://bit.ly/3dhKOTu

Lipovetsky, G., y Vargas-Llosa, M. (2012). ¿Alta cultura o cultura de masas? Letras libres, 130. https://bit.ly/2zFoP02

Martel, F. (2011). Cultura mainstream: cómo nacen los fenómenos de masas. Taurus.

Martín-Barbero, J. (2012). De la comunicación a la cultura: perder el "objeto" para ganar el proceso. Signo y Pensamiento, 30(60), 76-84. https://bit.ly/2YFwvYG

Martínez-López, J. S. (2011). Sociedad del entretenimiento (2): Construcción socio-histórica, definición y caracterización de las industrias que pertenecen a este sector. Revista LuciérnagaComunicación 6(3), 6-16. https://bit.ly/2NdAC8U

Morgan, M., y Shanahan, J. (2010). The State of Cultivation. Journal of Broadcasting \& Electronic Media, 54(2), 337-355. https://doi.org/10.1080/08838151003735018

Muñoz-Fernández, H. (2016). ¿Son arte las series de televisión? Index. Comunicación, 6(2), 69- 82. https://bit.ly/3tYw1M8

Neira, E. (2017). La guerra de las pantallas. Caimán cuadernos de cine, 62, 48-52.

Ovejero, J. (2012) La ética de la crueldad. Anagrama.

Pallarès-Piquer, M., Hernández, D., José-Castañeda, W., y Osorio, F. (2020). Vivir tras la catástrofe. El arte como intersección entre la imagen viviente y la conciencia. Una aproximación a la serie Chernobyl desde la ontología de la imagen. Arte, individuo y sociedad, 32 (3), 783-798. https://dx.doi.org/10.5209/aris.65826

Quintana, S. (2013). Modernidad, crueldad y exclusión del sujeto o las contradanzas del discurso capitalista. Revista de psicoanálisis, 13, 239-256. https://bit.ly/2CeHWip

Reviriego, C. (2011). Nuevas vidas para las series norteamericanas. Amplitud de miras. Caimán cuadernos de cine, 47, 6-8.

Rivera-García, A. (2016). Política y estética de la abyección: Una aproximación a partir de la imagen cinematográfica. Política común, 10. http://dx.doi.org/10.3998/pc.12322227.0010.012

Rivette, J. (1961) De l'abjection. Cahiers du cinéma, 120, 54-55.

Santos, A. (2019). Tiempos de ninguna edad. Distopía y cine. Cátedra.

Scott, A. O. (2010, 8 de septiembre). Are Films Bad, or Is TV Just Better? The New York Times. https://nyti.ms/3e6BeJr

Sontag, S. (2010). Ante el dolor de los demás. Contemporánea.

Starks, L. S. (2002). Cinema of cruelty: Powers of horror in Julie Taymor's Titus. En: The reel Shakespeare: Alternative cinema and theory, 121-143. Fairleigh Dickinson University Press.

Tait, S. (2008). Pornographies of violence? Internet spectatorship on body horror. Critical Studies in Media Communication, 25(1), 91-111. https//:doi.org/10.1080/15295030701851148

VanArendonk, K. (8 de julio de 2020). Peak Comfort The triumph of brazenly uncomplicated entertainment. New york magazine. http://bit.ly/3srTUKm 


\section{Semblanza de los autores}

Carlos Fernández-Rodríguez estudió en la Escuela de Cine y Audiovisuales de la Comunidad de Madrid (ECAM) y obtuvo un grado en Comunicación audiovisual por la Universidad de Sevilla (España). Tiene un Máster en Comunicación y Educación Audiovisual por la Universidad de Huelva y la Universidad internacional de Andalucía. Ha sido crítico cinematográfico como prensa para diversos medios en festivales de cine españoles como el SSIFF, el SEFF o el Festival de cine de terror de Sitges. Actualmente, se encuentra realizando un doctorado en Ciencias sociales y jurídicas (en el ámbito de la Comunicación) en la Universidad Rey Juan Carlos.

Luis M. Romero-Rodríguez es profesor en el departamento de Comunicación y sociología en la Universidad Rey Juan Carlos y Profesor invitado en ESAI Business School, Universidad Espíritu Santo. Tiene un doctorado en Comunicación por las universidades de Huelva, Sevilla, Málaga y Cádiz (España), y Máster en Comunicación Social por la Universidad de Almería (España).

Belén Puebla Martínez es profesora e investigadora de la Universidad Rey Juan Carlos. Investigadora Principal del Grupo de Investigación Consolidado "Innovación en Innovación, Educación y Comunicación de la Universidad Rey Juan, (INECO). Doctora en Ciencias de la Comunicación por la URJC. Master en Comunicación y problemas socioculturales. Licenciada en Periodismo y en Comunicación Audiovisual por URJC. Es especialista en el estudio de la ficción televisiva española, en el análisis de los medios de comunicación especialmente en prensa y televisión, en el estudio de los métodos analíticos de investigación en comunicación social y en didácticas innovadoras, entre otras líneas de investigación. Directora de la revista científica Index.comunicación. 